\title{
A "Mimic Octopus" in the Atlantic: Flatfish Mimicry and Camouflage by Macrotritopus defilippi
}

\author{
ROGER T. HANLON ${ }^{1, *}$, ANYA C. WATSON ${ }^{1}$, AND ALEXANDRA BARBOSA ${ }^{1,2,} \dagger$ \\ ${ }^{1}$ Marine Resources Center, Marine Biological Laboratory, Woods Hole, Massachusetts 02540; and \\ ${ }^{2}$ ICBAS_Institute of Biomedical Sciences Abel Salazar, University of Porto, Portugal
}

\begin{abstract}
The sand-dwelling octopus Macrotritopus defilippi was filmed or photographed in five Caribbean locations mimicking the swimming behavior (posture, style, speed, duration) and coloration of the common, sand-dwelling flounder Bothus lunatus. Each species was exceptionally well camouflaged when stationary, and details of camouflaging techniques are described for M. defilippi. Octopuses implemented flounder mimicry only during swimming, when their movement would give away camouflage in this open sandy habitat. Thus, both camouflage and fish mimicry were used by the octopuses as a primary defense against visual predators. This is the first documentation of flounder mimicry by an Atlantic octopus, and only the fourth convincing case of mimicry for cephalopods, a taxon renowned for its polyphenism that is implemented mainly by neurally controlled skin patterning, but also-as shown here-by their soft flexible bodies.
\end{abstract}

\section{Introduction}

Movement gives away camouflage under most circumstances (see Cott, 1940). For soft-bodied, vulnerable octopuses in open habitats such as sand plains, this poses a problem because daily foraging requires movement without the protection of habitat structure. For example, octopuses in many habitats take advantage of corals, algae, rock, etc., to implement slow, camouflaged stealth movements (e.g., Hanlon et al., 1999). Here we report observations from five widespread locations that the Atlantic longarm octopus, Macrotritopus defilippi Verany, 1851, when swimming on

Received 5 February 2009; accepted 21 September 2009.

* To whom correspondence should be addressed. E-mail: rhanlon@ mbl.edu

† Current address: UMR 7179, National Center of Scientific Research, National Museum of Natural History, France. open sand plains, apparently mimicked the swimming behavior, posture, and coloration of a common flatfish, the plate fish (or peacock flounder) Bothus lunatus (Linnaeus, 1758).

Mimicry is commonly understood to imply the resemblance of one animal (the mimic) to another (the model) such that a third animal is deceived by their physical similarity into confusing the two ( $c f$. Wickler, 1968; Edmunds, 1974). Only recently was mimicry demonstrated in octopus, and these were sand-dwelling species in the Indo-Pacific. The mimic octopus, Thaumoctopus mimicus, and an unidentified octopus-possibly the octopus referred to by Norman (2000) as "White V octopus, Octopus sp. 18" or by Hanlon et al. (2008) as "blandopus"-were documented as mimicking flounder swimming in Indonesia (Norman et al., 2001; Norman and Hochberg, 2005; Hanlon et al., 2008). Norman et al. (2001) and some authors in the non-scientific literature (e.g., Steene, 1998) have suggested other wideranging cases of mimicry by Thaumoctopus mimicus, although these remain unsubstantiated. Hanlon et al. (2008) suggested the possibility that, when motionless, both octopus species might be mimicking some of the few sessile organisms present on the open sand plains: colonial tunicates, sponges, and tubes of polychaete worms. Among cuttlefish, small males of Sepia apama, the giant Australian cuttlefish, were found to mimic the posture and coloration of females to visually deceive the large consort males and obtain matings (Norman et al., 1999; Hall and Hanlon, 2002); and Hanlon et al. (2005) demonstrated that this sexual mimicry led to increased mate choice by the female as well as to immediate fertilizations.

Macrotritopus defilippi is a small, poorly known sand dweller that attains sizes up to $90 \mathrm{~mm}$ in mantle length. The paralarvae of this species were, for 100 years, reported as "macrotritopus larvae" with unknown adult identity (see 

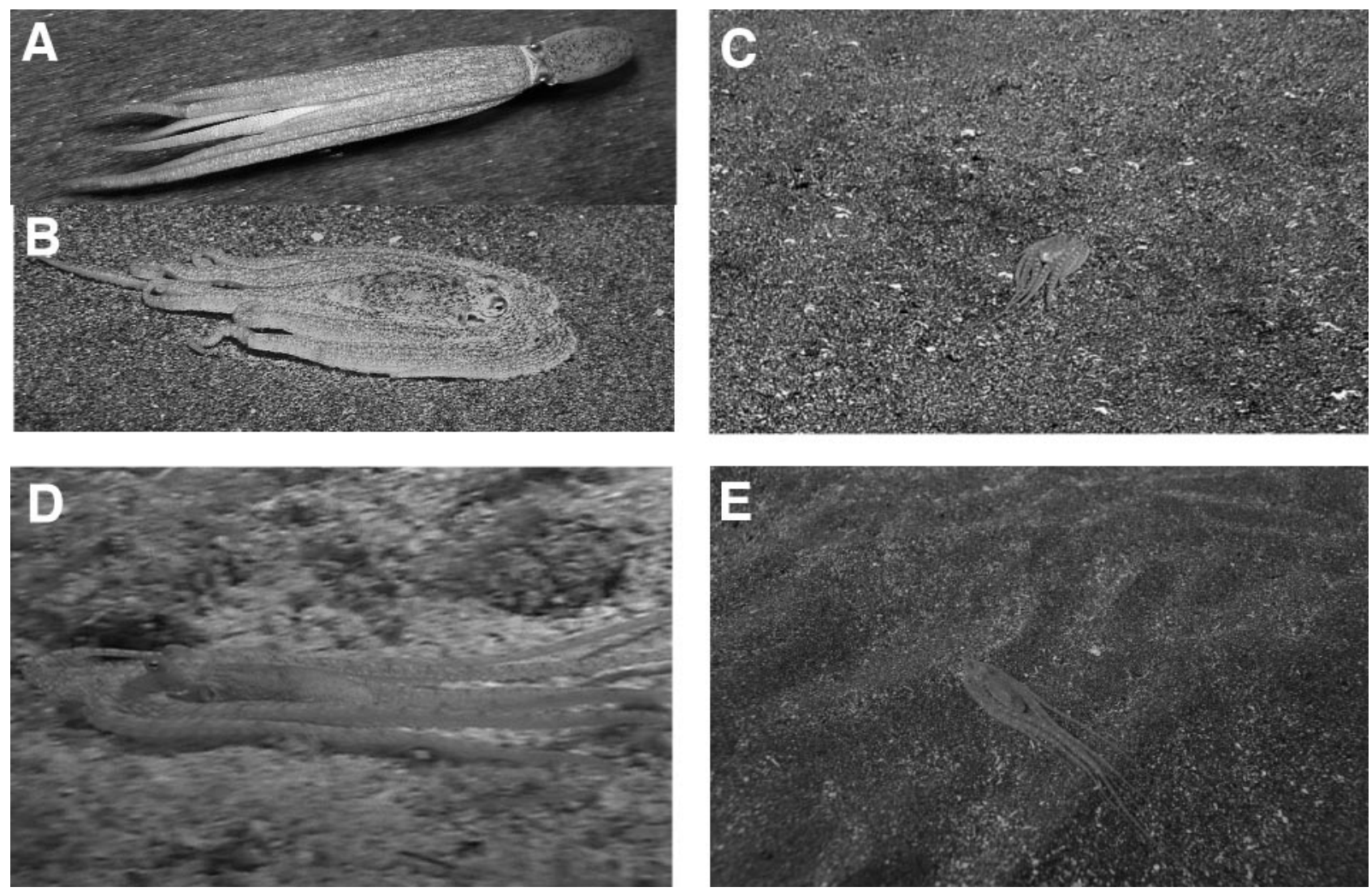

Figure 1. Macrotritopus defilippi performing flounder mimicry. (A) Normal backward swimming; October 2000 Dominica; copyright Ned DeLoach. (B) Apparent flounder mimicry; October 2000, Dominica; copyright Paul Humann. (C) Apparent flounder mimicry; December 2004, Saba. Photo by M. Chammaa. (D) Video frame grab video, showing how the octopus hugs the contour of the bottom while mimicking flounder; October 2005, Howard and Michelle Hall. (E) October 2005, Saba; note how the octopus is flattening itself along every ripple of the sand. Photo by R. Hanlon.

Grimpe, 1922; Rees, 1954). Hanlon et al. (1985) captured live macrotritopus paralarvae at night-lighting stations in St. Croix, Virgin Islands, transported them to the laboratory, and cultured one to adult size. It was identified as Octopus defilippi (the genus was subsequently changed) on the basis of the very long arms, small body size, skin sculpture, and body patterning (Hanlon, 1988). However, aside from the information reported by Hanlon et al. (1985) in the laboratory culture experiment, essentially nothing is known about the biology of this species, especially under natural conditions.

\section{Materials and Methods}

\section{Sequence of discovery}

Apparent flounder mimicry in Macrotritopus defilippi was first documented by photographers Paul Humann and Ned DeLoach in 2000 at Dominica Island (Caribbean Sea, Lesser Antilles, $15^{\circ} 25 \mathrm{~N}, 61^{\circ} 20 \mathrm{~W}$ ) and reported in their commercial book on identification of marine invertebrates of the Caribbean (Humann and DeLoach, 2002). They pub- lished pictures showing normal backward swimming (Fig. 1A) as well as forward swimming with distinctive flattening of the body, the eight arms streaming backward in the shape of a flatfish (Fig. 1B), and they reported that the species was day-active and "may attempt to camouflage identity by mimicking the shape and movements of flounder."

In December 2004, one of us (RTH) was diving with volunteers on a sand plain at Saba Island, Netherlands Antilles, and a volunteer-Michael Chamma-acquired Figure $1 \mathrm{C}$ indicating the possibility that the octopus might be mimicking a flounder. Consequently, in October 2005, the coauthors led a group of six volunteers to search the sand plains off Saba for mimicry by octopus. Subsequently, in April 2006, professional filmmaker Howard Hall provided us with a short video clip taken at night, at a depth of about 13 m, near Lighthouse Reef off Belize, in which a small individual of $M$. defilippi was believed to be mimicking flounder swimming (Fig. 1D). In June 2006, professional diver and photographer Dee Scarr observed one octopus apparently mimicking flounder swimming in Bonaire, Netherlands Antilles; subsequent photographs confirmed 
the identity of this octopus as $M$. defilippi. In April, May, and June 2008, diver and photographer Lazaro Ruda videotaped 21 sequences of short bursts of flounder-like swimming by $M$. defilippi; the location was the intracoastal waterway at Phil Foster Park, Riviera Beach, Florida. Collectively, $M$. defilippi individuals in five Caribbean locations have been photographed or videotaped.

\section{Field work}

During one week in October 2005, the coauthors and six volunteer divers searched for $M$. defilippi on sand plains, coral reefs, algal plains, and near-shore habitats off the coast of Saba in the Netherlands Antilles (17 $\left.{ }^{\circ} 38 \mathrm{~N}, 63^{\circ} 13 \mathrm{~W}\right)$. Overall, 51 diver-hours were spent searching for octopuses on or adjacent to sand plains. All dives were completed in daylight at depths ranging from 10 to $15 \mathrm{~m}$. One individual of $M$. defilippi was found in mid-afternoon on a sand plain at $12 \mathrm{~m}$ amidst the Saba boat mooring field (Fig. 1E). This octopus was estimated from photographs to be $2.5 \mathrm{~cm}$ in mantle length (total length, TL, $11 \mathrm{~cm}$ ). Other search sites and near-shore habitats produced no results. The shorterarmed Amphioctopus burryi was also common on this sand plain, and $O$. vulgaris was found around Saba, although not in these open sand plains (species identifications were determined by skin patterns and behavior; see Hanlon, 1988; no animals were collected). Small flounder, Bothus lunatus, were plentiful and were also videotaped and photographed on these sand plains; they were identified by using fish identification guides (e.g., Humann and DeLoach, 2002) and photographs and references in Fishbase (Frose and Pauly, 2009). M. defilippi and B. lunatus were photographed using a Canon EOS-1Ds Mark II and video-taped using a Sony VX1000 (mini-digital video format). Video was played back slowly and images were extracted and then formatted in Adobe Photoshop.

\section{Results}

\section{Comparisons of swimming between octopus and flounder}

With video, we compared swimming duration, swimming speed, swimming style, posture, and coloration between octopus (Macrotritopus defilippi) and flounder (Bothus lunatus). This fish species is one of the most common sand dwellers throughout the Caribbean, and the genus Bothus is a marine teleost known to have a modest color and pattern repertoire that can change in 2-8 s (Froese and Pauly, 2009; Ramachandran et al., 1996).

Swimming style and posture were distinctive (Fig. 2). Small flounders typically performed what we may term "contour swimming" by swimming along the bottom contour amidst the sand ripples; that is, they mostly hugged the bottom regardless of its wave-like contours (Fig. 2A, B). The octopuses did the same thing; instead of swimming at a constant altitude off the substrate, they swam in a precise manner along its shape (Fig. 2C, D; sample video can be viewed at http://www.biolbull.org/supplemental/). During this type of swimming, the octopus eyes were also in the same approximate position as the eyes of the flounder, which are both on the left side in the family Bothidae (order Pleuronectiformes).

Both the fish and the octopus swam in short bouts, interspersed with motionless camouflage. Swimming durations of two flounders ( $c a .10-30 \mathrm{~cm}$ TL) in Saba were determined, one from seven video sequences and the other from three sequences (Fig. 2E). Figure 2F illustrates the durations and stop times for three octopus swimming sequences ( $n=2$ individual octopuses). The Saba octopus ( $c a$. $11 \mathrm{~cm} \mathrm{TL}$ ) swim durations were acquired from two video clips (92 s and $44 \mathrm{~s}$ ) in which it performed flounderswimming 11 and 9 times in succession. The octopus in Belize (similar in size to the Saba octopus) performed flounder-like swimming 8 times in succession during a 35-s video clip. Overall, the median swimming durations (and minimum/maximum) were $2 \mathrm{~s}(1-20)$ for octopus and $6 \mathrm{~s}$ (3-43) for flounder. Stop durations between swims were similar but highly variable: $2 \mathrm{~s}(1-13)$ for octopus; $3 \mathrm{~s}(1-8)$ for flounder. Thus, when comparing the swimming durations as well as the stop durations during swimming sequences, the octopus and fish were roughly similar.

The Florida octopuses $(n>5)$ were relatively easier to find in that location (higher population density, shallow water) and were often out foraging in the sandy shallow (2-m) habitat. Volunteer Lazaro Ruda filmed only in brief segments (via snorkeling, not scuba) but the video provided durations of flounder-like swimming: mean for 21 episodes was $3 \mathrm{~s}$ (range 2-7). He also filmed M. defilippi performing typical backward swimming as photographed by N. DeLoach (Fig. 1A).

Swimming speeds were as follows. Both the Saba and Belize octopuses had speeds averaging about $0.8 \mathrm{TL} / \mathrm{s}$. With the estimated size of $11 \mathrm{~cm}$ TL for the Saba octopus, this translates roughly to $9 \mathrm{~cm} / \mathrm{s}$. The Belize octopus was measured from five episodes as swimming at $0.8 \mathrm{TL}$ - the same as the Saba octopus. Four flounders swam from 1 to $2 \mathrm{TL} / \mathrm{s}$, or roughly $12-15 \mathrm{~cm} / \mathrm{s}$. Overall, flounders swam slightly faster than octopuses, but within an order of magnitude.

\section{Camouflage}

The octopuses maintained a camouflaged body pattern while swimming as well as when stopped. As noted in Figures 1 and 2, the animals were a Uniform Light or Stippled pattern that closely resembled the sand substrate. The color (light yellow/ brown), pattern, and brightness matches to the sand were excellent, as judged by the human eye viewing the octopuses in situ and from photographic color images. In between each swimming session, the octopus stopped, often spread its arms, 

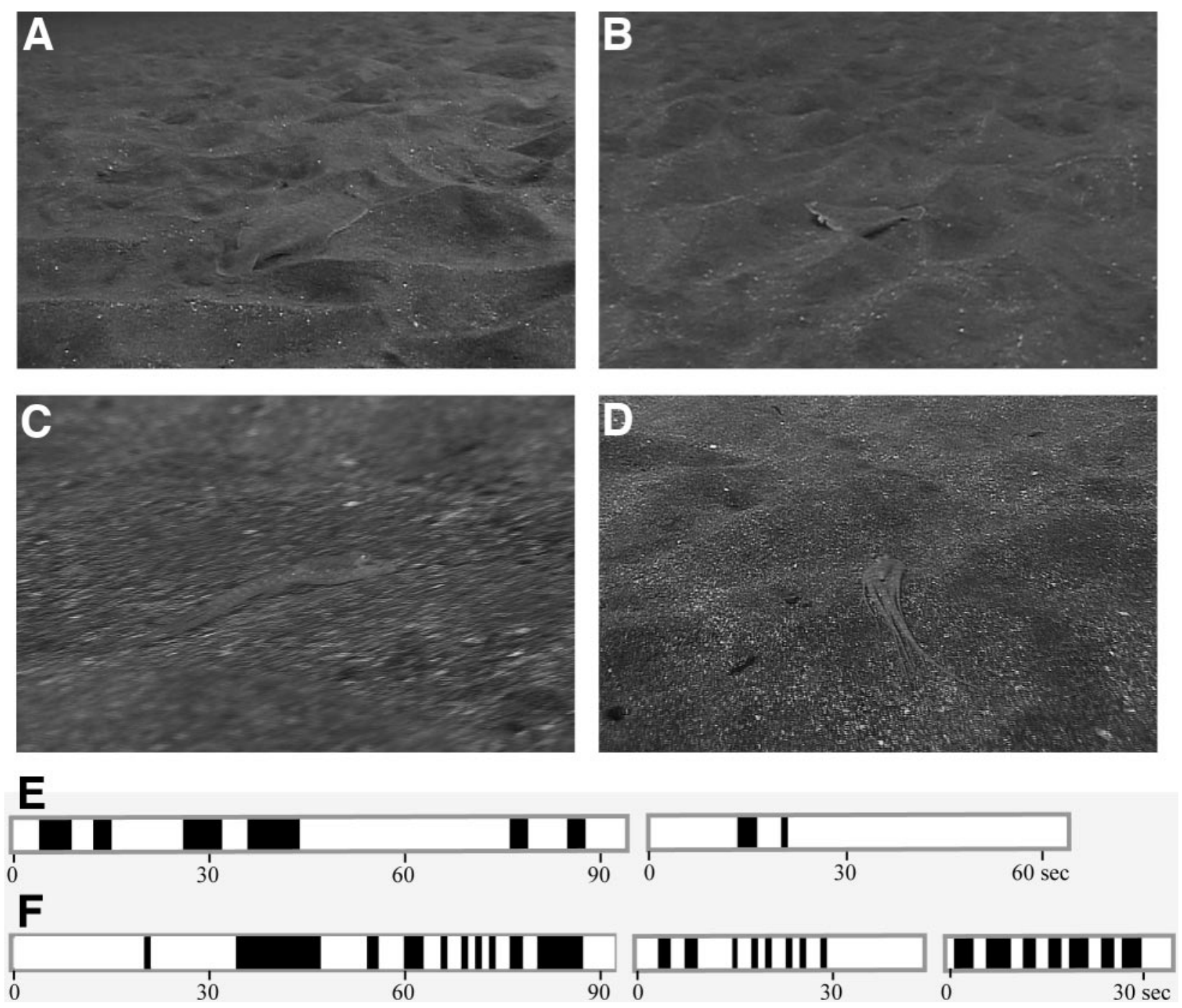

Figure 2. Contour swimming by flounder and octopus. (A) The flounder Bothus lunatus showing contour swimming by hugging the ripples of the sand. (B) Similar to A but at a different dive site in Saba. (C) Macrotritopus defilippi mimicking flounder with contour swimming amidst the ripples of the sand. (D) Same octopus as in $\mathrm{C}$ viewed from above; note how lack of shadow indicates that all parts of the body are nearly in contact with the irregular sand bottom. (E) Seven (white bars) and three sequences of flounder swimming by two B. lunatus in Saba. (F) Eleven and nine video sequences of flounder mimicry (white bars) by one Octopus defilippi in Saba (first two sequences), and eight sequences by another octopus in Belize (third sequence). All times in seconds.

and became highly camouflaged. Figure 3 illustrates the high degree of camouflage of the flounder and the octopus when motionless. The flounders have small ovoid skin components that are, in small fish, comparably sized to small sand and gravel in this habitat, and thus they provide a close resemblance to the background. The octopuses have far more control of their skin components and on this background produce a light, small-scale mottle skin pattern replete with small papillae (see Allen et al., 2009) that further enhance the textured appearance of the skin (see close-up in Fig. 3D). Note the light/dark recurring bars along the length of the arm in Figure $3 \mathrm{D}$; this blends in well with the light and dark pebbles that constitute much of this "sandy" substrate. When viewed from a distance (i.e. ca. $1 \mathrm{~m}$, as in Fig. 3C), the octopus pattern appears as a Uniform Light body pattern that closely resembles the background and produces the camouflage effect.

It is noteworthy that, in some video segments (Fig. 4), the octopus showed a relatively large white leucophore patch at the tip of its mantle, which produced a disruptive coloration effect when viewed closely. In Figure $4 \mathrm{~A}-\mathrm{C}$, there were small white rocks in the immediate visual background. Thus, for distance viewing, the octopus white marking appeared as a random sample of other white objects in the background.

When initially encountered, the octopus found in Saba 

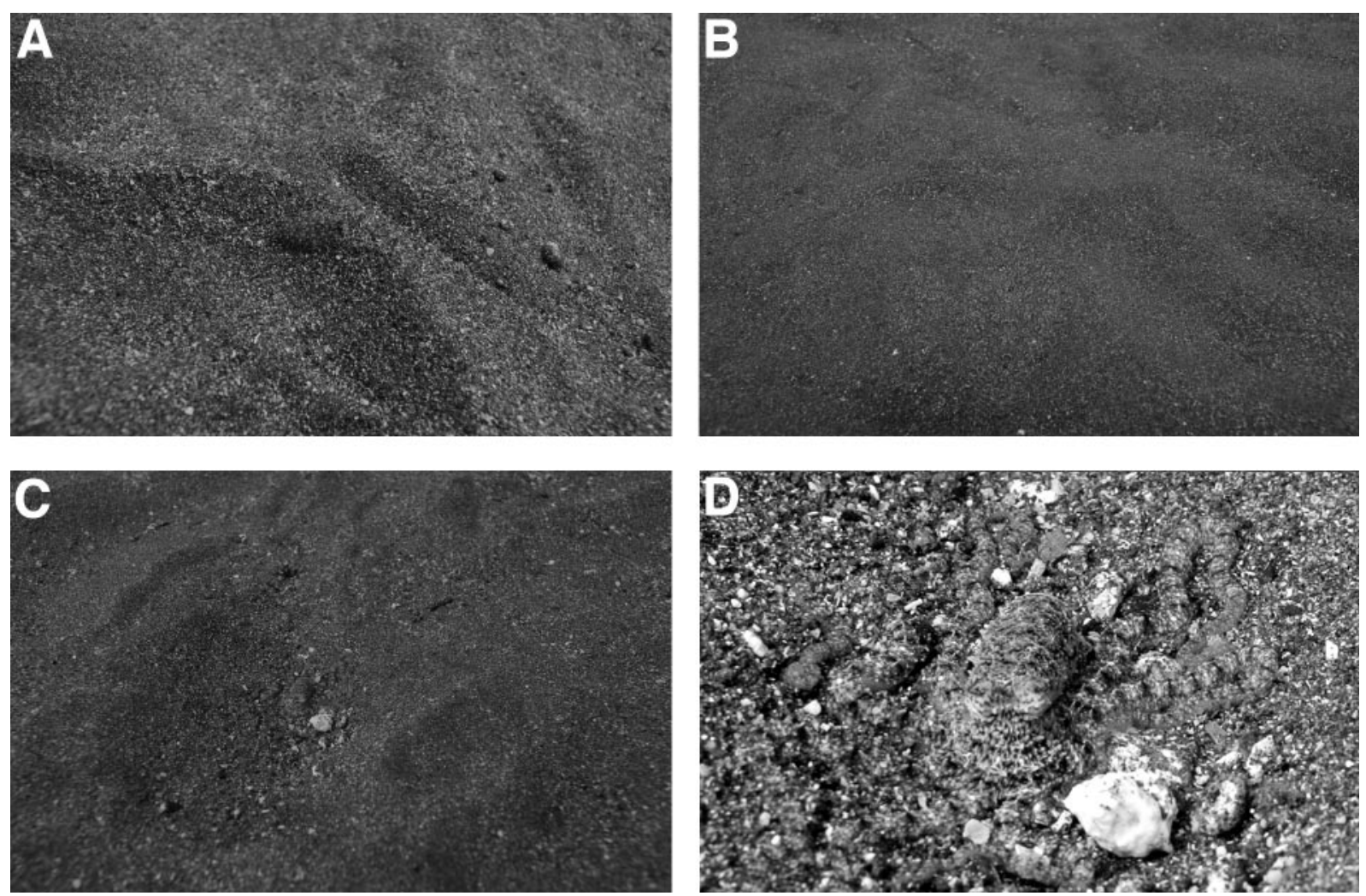

Figure 3. Camouflage by flounder and octopus when stationary. (A) Very small Bothus lunatus (directly in center of image) matching the brightness, color, and pattern of the sand. (B) A larger B. lunatus (bottom center of image; $c a .23 \mathrm{~cm}$ total length) providing excellent general resemblance to the sand bottom. (C) Macrotritopus defilippi in center of image, completely exposed yet well camouflaged. (D) Close-up of the octopus in C; note the finely mottled body pattern, the dark bars on the arms, and the general difficulty of detecting the arms.

was flattened on the underside of an exposed rock sitting on the sand plain. This species is small and delicate in construction compared to other shallow-water octopuses in that region, and camouflage is likely to be its key defense. At the end of the sole Saba video sequence, it buried itself in the sand and disappeared, and no hole was seen there before or after the burying. Thus, the sand habitat posed no limitation on hiding spots.

\section{Some behavioral correlates from laboratory culture of Macrotritopus defilippi}

In 1978, one female paralarva was caught in St. Croix, U.S. Virgin Islands, and transported to Texas and cultured to adulthood (Hanlon et al., 1985). As shown in Figure 5, the skin sculpture and patterning are similar to those in our field samples, including the white leucophore marking at the
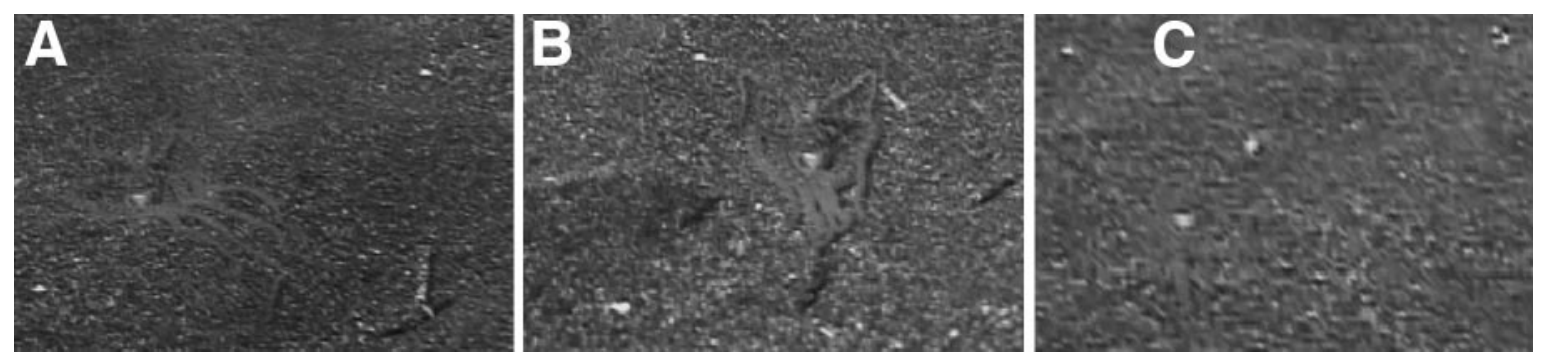

Figure 4. Camouflage and white markings in Macrotritopus defilippi. (A, B) Video images of stationary octopus with arms spread differently. Note the bright white leucophore patch at the apex of the mantle and other white pebbles nearby. (C) Video image of octopus (directly below the letter C) in which the white patch of leucophores on the mantle stand out, but which also resemble 2-3 other white pebbles in the visual background. 

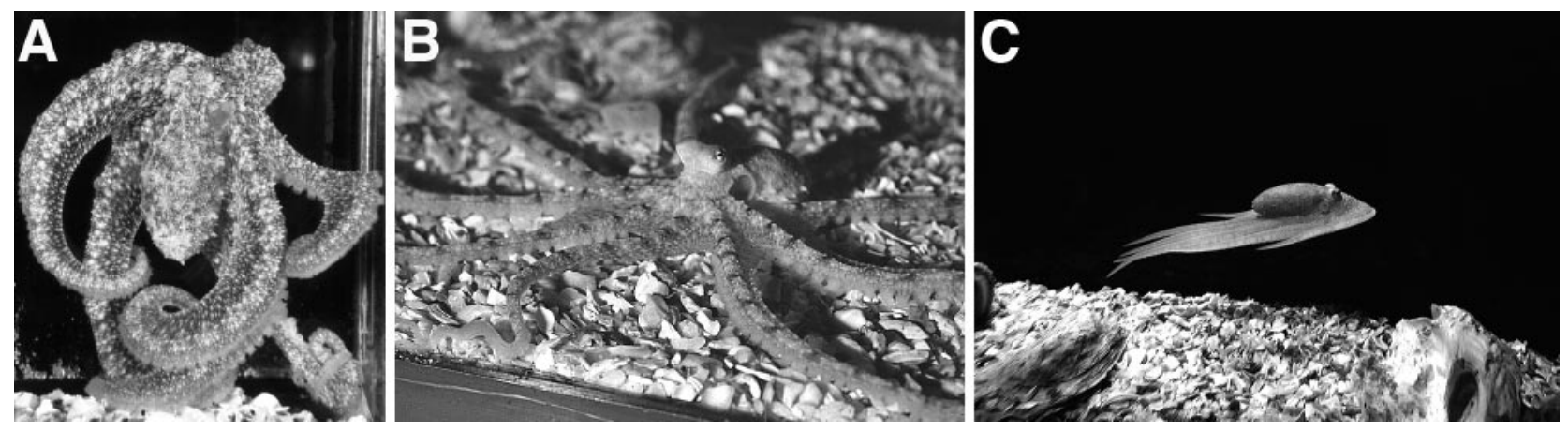

Figure 5. Images of laboratory-reared Macrotritopus defilippi. (A) Juvenile female showing a typical mottle coloration with fine papillae over the body and small-scale bluish-white leucophore and iridophore markings throughout the mantle, head, and arms. Note particularly the faint expression of the white leucophore patch at the distal 1/5th of the mantle (and compare this patch with its expression in Figs. 1A, 2B, and 4A, B, C. (B) Juvenile spreading its arms in the same manner as in the field (compare Fig. 4A); note the dark arm bars that disrupt the lengthwise form of each arm (compare Fig. 3D). (C) Flounder-like swimming in a laboratory-reared female (photo credits: John Forsythe, A, B; Roger Hanlon, C).

distal end of the mantle (Fig. 5A; compare Fig. 4A-C). The small dark arm bars (characteristic of the species; Hanlon, 1988) are also evident in Figure 5B, as they are in Figure 3D. Notably, Figure 5C indicates streamlined forward swimming (similar to our recent underwater observations reported herein) in a laboratory-reared octopus, yet this octopus had never seen a flounder.

\section{Discussion}

\section{Primary defense tactics and camouflage while moving}

Octopus defense against predators has been summarized to involve three general stages: (i) camouflage as primary defense; (ii) flight or deimatic displays as the first phase of secondary defense when the octopus is closely approached by a predator; and (iii) protean escape behavior as the second phase of secondary defense in which erratic, unpredictable maneuvers are undertaken to upset target prediction by the predator (Hanlon and Messenger, 1996; their fig. 5.1). Camouflage comprises several tactics, most of which involve body patterning and postures that enable a cephalopod to avoid visual detection (via background matching) or recognition (via disruptive coloration) while stationary. Yet octopuses, like all animals, have to move. Visual predators have motion detectors in their visual system (e.g., Hailman, 1977; Borst and Egelhaaf, 1989; Srinivasan and Davey, 1995; Stevens et al., 2007), and thus camouflage tactics must accommodate this fact to remain effective.

Cephalopods have evolved several tactics to achieve camouflage while moving. Octopuses tend to move very slowly, with great stealth, when foraging in habitats with structure, such as coral or rock reefs (Hanlon et al., 1999). Presumably such slow movements, combined with refined camouflage patterning and postures, enhance their chances of not being detected by most visual predators. Other octo- pus species will move across open areas, but they take on the general appearance of the few other objects that occur in those habitats. For example, often the octopus (Hanlon and Messenger, 1996; Hanlon et al., 1999; Huffard et al., 2005; Huffard, 2006) or cuttlefish (Hanlon et al., 2009) tends to look like inedible objects such as rocks, coral, or clumps of algae, a camouflage mechanism known as masquerade (Stevens and Merilaita, 2009a). Octopus cyanea moves slowly or fast according to the artificial motion of the play of light caused by surface ripple (Hanlon et al., 1999).

To evolve a camouflage tactic that is effective during swift movement is more challenging, and the nature of the visual deception may be different than during still camouflage or slow-moving stealth camouflage. Swift bipedal walking in a camouflaged pattern and posture has been reported in Abdopus aculeatus and Amphioctopus marginatus at $13 \mathrm{~cm} / \mathrm{s}$ and $14 \mathrm{~cm} / \mathrm{s}$, respectively (Huffard, 2006). These speeds (in upright walking posture) are faster than those of streamlined swimming reported here for $M$. defilippi at $9 \mathrm{~cm} / \mathrm{s}$. A. aculeatus also performs "contour swimming" in the dorsoventral compressed body shape (like that reported here for $M$. defilippi), but this was not reported as flatfish mimicry.

We know of three octopus species-each living on open featureless sand plains in different oceans-that have evolved rapid flatfish swimming mimicry. Two tropical octopus species (the "mimic octopus" Thaumoctopus mimicus and an undescribed, but similar, species called blandopus or White V Octopus sp. 18) in Indonesia and vicinity are reported to mimic swimming flatfish (Norman et al., 1999; Hanlon et al., 2008). In this paper, we report a third species-M. defilippi in the Caribbean -mimicking a swimming flatfish, the common flounder Bothus lunatus, which itself has exceptional and changeable camouflage and is common on sand plains. 
Given these results and those of Norman et al. (1999) and Hanlon et al. (2008), we must add flatfish mimicry while swimming to the category of primary defense, according to the three stages of defense proposed by Hanlon and Messenger (1996). Previously, primary defense of cephalopods was considered to be camouflage while stationary.

\section{Mimicry}

There are "good mimics" and "poor mimics" among animals, as determined by a very precise or a less precise resemblance (Edmunds, 2000), and the three octopus mimics reported in the literature span this range. $M$. defilippi is a good-if not excellent—mimic of B. lunatus in all aspects of coloration as well as most aspects of swimming (Figs. 1-3). The undescribed Indo-Pacific octopus dubbed "blandopus" (or White V Octopus sp. 18) is also a good-or high fidelity-mimic of Bothus mancus, while Thauoctopus mimicus was judged to be a more general (perhaps even poor) mimic of B. mancus in Indonesia because its coloration pattern did not often match that of the flounder (Hanlon et al., 2008), although it may better match the patterning of other flatfish in that geographic range. Gilbert (2005) and Stevens (2007) commented on "imperfect mimicry," citing the possibility that it may be an adaptation to combine camouflage with some level of Batesian mimicry should concealment fail; it is not known whether any of the mimic octopuses are toxic.

Most researchers draw attention to the coloration and pattern of mimics, but we are also impressed with the contortions of the octopus body and the striking similarities in posture, speed, duration, and undulations to the flounder swimming. Octopuses have no large rigid structures in their bodies (as do cuttlefish with a cuttlebone, and squids with a gladius, both of which span the length of the mantle), thus their body shape is highly malleable. Cephalopod arms and tentacles achieve high degrees of freedom of bending because they are muscular hydrostats (Kier and Smith, 1985). Thus, a good deal of polyphenism is also produced by body shape and posture in octopuses (e.g., Hanlon et al., 1999; Huffard, 2006, 2007), and in this case by the octopus tapering its eight arms backward and undulating them similar to the flounder's body and fins. The forward swimming with trailing arms could also be a biomechanical byproduct of moving a soft body close to a contoured surface using lift, rather than behavioral intent, to mimic (Huffard, 2006). However, most octopus species that have been observed by divers (many dozens worldwide) do not swim like this. Moreover, we have photographic and video evidence that M. defilippi performs the more typical "backward swimming" (Fig. 1A) shown by all shallow-water octopus species.

Octopuses, in general, move fast or slow with at least 13 postures, and the forward swimming observed here is re- ferred to as "dorsoventrally compressed" swimming, and may provide several advantages (Huffard, 2007): (i) faster and more efficient swimming, due to lift, compared to other forms of swimming; (ii) allowing an octopuses' eyes to be directed forward while foraging; (iii) more easily exposing arms, which can be regenerated, to predation instead of the more vulnerable body (at least two of the four species known to contour swim can autotomize their arms, Norman and Hochberg, 2005; Huffard, 2007); and (iv) keeping the individual close to the substrate so that it can quickly stop and camouflage itself, find shelter, or bury itself into the sand should a predator be detected. We add to this list the possible advantage of leaving the octopus in a good posture to launch a forward lurching attack on prey, in which the first two pairs of arms perform a pinching movement to envelop benthic crustacean prey; such attacks were filmed several times by volunteer L. Ruda in Florida during this study. Huffard (2006) described forward swimming form in Abdopus aculeatus. Flatfish also benefit from lift during swimming (Webb, 2002). In our observations, flounders of comparable size are more powerful and efficient swimmers than octopuses; the M. defilippi individual in Saba developed a high ventilation rate shortly into its sequence of flounder mimicry and appeared to fatigue noticeably, whereas small Bothus individuals did not. Certain physiological and biomechanical inefficiencies of octopuses (Wells, 1990) may impose a need to rest, which may explain their shorter and more variable swimming durations.

Locomotor mimicry has been described in droneflies, which mimic the flight patterns of honeybees (Golding et $a l ., 2001$, and references therein). There are other documented cases of locomotor mimicry among butterflies (e.g., the mimetic Heliconius spp.) that show morphological, kinematic, and aerodynamic convergence with their models (e.g., Srygley, 1999). The swimming style, speed, and stopand-go behaviors of $M$. defilippi in this study and the Thaumoctopus mimicus and Species 18 in the Indo-Pacific study (Hanlon et al., 2008) all show numerous similarities to the swimming behavior of Bothus species in their respective habitats. The locomotor mimicry of flatfish by octopuses represents a phylogenetic distance greater than that found in the insect examples.

Overall, only four cases of cephalopod mimicry are supported with some semblance of data in the form of video counts, measurements, and comparisons: the two octopus cases cited above; the $M$. defilippi described in this paper; and the giant Australian cuttlefish, Sepia apama, the small males of which mimic females to deceive large consort males and to gain access to matings (Norman et al., 2001). Hanlon et al. (2005) provided behavioral and genetic data to firmly establish the selective advantage of sexual mimicry in Sepia apama. These cases further support the accepted notion of behavioral convergence between cephalopods and teleost fishes (Packard, 1972). There are numerous anec- 
dotal suggestions of mimicry in cephalopods. Briefly, these include possible mimicry of one parrotfish species by $O c$ topus cyanea when swimming backward and another parrotfish species when swimming frontward (Hanlon and Messenger, 1996; Hanlon et al., 1999); possible mimicry of one grouper species by Octopus insularis while swimming backward (Krajewski et al., 2009); squid Sepioteuthis sepioidea parrotfish mimicry in an apparent attempt to get closer to small fishes that they were preying upon (Hanlon and Messenger, 1996). Moreover, for Thaumoctopus mimicus, the Indo-Pacific mimic octopus, there have been suggestions (some very casual) that this species may mimic mantids, banded sea snakes, lionfish, seahorses, crocodile snake eels, stingrays, sand anemones, feather stars, brittle stars, jellyfish, giant crabs, nudibranchs, sponges, polychaete worm tubes, and colonial tunicates (Steene, 1998; Norman, 2000; Norman et al., 2001; Norman and Hochberg, 2005; Hanlon et al., 2008). Some of these suggestions may eventually be supported by rigorous observation and video data, but at present none of them are compelling examples of mimicry sensu stricto (Wickler, 1968; Edmunds, 2000).

What type of mimicry might be occurring between octopuses and flatfish? Batesian mimicry is a form of defensive mimicry in which there is a resemblance of a palatable animal to a noxious animal such that a predator is deceived into avoiding the mimic because it mistakes it for the noxious model (Wickler, 1968; Edmunds, 2000). Unfortunately there is only one direct behavioral anecdote of predation on the species reported here: a Japanese film crew in Lembeh, North Sulawesi, Indonesia, observed a large flounder (Bothidae) attacking a Thaumoctopus individual and nearly swallowing it before regurgitating it (reason unknown). Other predators that might prey upon the three known octopus mimics are unknown. Neither Bothus mancus in the Indo-Pacific nor Bothus lunatus in the Caribbean are poisonous; thus it is impossible to invoke Batesian mimicry as the model for these interactions. Nor can Müllerian mimicry (i.e., two unrelated harmful species adapting the same warning coloration to ward off a common predator) form the basis for an explanation. There is continual debate over the definitions and types of mimicry-especially regarding the distinctions between camouflage and mimicry (e. g., Endler, 1981)—which has led Starrett (1993) to suggest an alternative term and concept called Adaptive Resemblance, which emphasizes fulfillment of only one condition: that fitness is gained due to some selective advantage imparted by resemblance to another animal.

Cephalopod mimicry, or adaptive resemblance, requires a great deal more study. One possible explanation of octopus mimicry of flatfish, raised by Huffard (2006), is that many smaller gape predators that could bite a portion of a soft octopus would mistake the octopus for a larger rigid flatfish, which would be too much of a mouthful. The stop-and-go swimming, with similar speeds and durations, were shared by fish and octopus in our observations. For a predator observing from a distance of 1-3 $\mathrm{m}$, these sequences of behavior with indistinguishable skin patterns and swimming behavior must look very similar.

Is flounder mimicry innate or learned? Although no one has an answer, Figure 5C suggests the former. This animal was captured in the field at a very small size (latter stages of planktonic; Hanlon et al., 1985) and reared to mature adult stage. It had no access whatsoever to flounders in its laboratory existence, yet we have several notes and the photograph in Figure 5C showing frontward streamlined swimming posture nearly identical to current field observations and to flounder swimming. At that time, we had no notion of flounder mimicry, but it is noteworthy that the octopus performed this motion even in the very small tank that it was reared in. It would be possible to test this ability with laboratory-reared M. defilippi, although the life history is so obscure that acquisition of eggs or gravid females would be challenging at this time.

\section{Camouflage by octopuses and flounders}

For animals on or near a substrate, two general mechanisms of camouflage are recognized, background matching and disruptive coloration (e.g., Thayer, 1909; Cott, 1940; Stevens et al., 2004), and cephalopods use both mechanisms (Hanlon and Messenger, 1996). In this study, background matching to the substrate was observed in B. lunatus and $M$. defilippi; that is, both animals had skin patterns and coloration that closely resembled the surrounding sand (Figs. $1-3)$. For cephalopods, the terminology in this case is that the octopus was showing a Uniform body pattern (i.e., a pattern with little or no contrast; Hanlon, 2007) on a uniform background (sand) to achieve general background matching (see further explanations in Hanlon et al., 2009). Another explanation is that the octopus's skin components represented a random sample of the very small sand grains in the background (e.g., Endler, 1978). One major advantage of rapid neural polyphenism (Hanlon and Messenger, 1996; Hanlon et al., 1999) is that an octopus can regulate its camouflage for each microhabitat in which it settles. Thus, as seen in Figure 3C and D, the octopus has increased the size of the light and dark skin elements to match those of the slightly larger sand and gravel in a depression that is surrounded by fine-grained sand. Upon close inspection (equivalent to near viewing by a predator), the octopus pattern is what we term Mottle, which is characterized by small-scale light and dark patches of moderate contrast (Hanlon, 2007).

The octopus in panels C and D of Figure 3 was thus switching from Uniform to Mottle patterning, depending upon its immediate visual surrounds on the sand plain. Moreover, as shown in Figure 4, the octopus was turning on 
a conspicuous white patch on its distal mantle. This white patch resembled other white sand particles in the immediate surroundings and so could be perceived as a random sample of white objects in the visual field. Thus, we have perhaps two examples of background matching: the whole animal generally resembling the sand background, or the white patch generally resembling the small white objects in the sand background. If one would cut the animal out from its background and describe the body pattern, then this might be considered a disruptive body pattern (defeats recognition of the animal's shape) due to the presence of the conspicuous high-contrast white patch on the mantle (Hanlon et al., 2009). It is possible, but certainly not proven, that a predator within close striking distance of the octopus in Figure 4 would be visually deceived via disruption (i.e., a white disjunct object, arms spread and generally resembling sand) of the recognizable octopus form, and thus not attack it. This fits the theoretical model of disruptive camouflage mechanism (see Stevens et al., 2007; Stevens and Merilaita, $2009 \mathrm{~b}$, and several papers in that volume), but it requires experimentation for verification.

By any account, $M$. defilippi, like all shallow-water octopuses in diverse visual habitats, has sophisticated dynamic camouflage capabilities. It combined stationary, slow/ stealth, and fast-swimming camouflage in the same open habitat. The camouflage diversity of B. lunatus has not been systematically studied to our knowledge, although we are aware of its fine-tuned changes that are equivalent to Uniform and Mottle patterns in the octopus; this fish species is particularly known for its warning display of bright blue iridescence throughout the skin (Froese and Pauly, 2009). Some details of camouflaged pattern change were nicely documented in Bothus ocellatus (a sympatric Caribbean sand dweller) by Ramachandran et al. (1996).

The final defensive behavior observed in M. defilippi was burying into the sandy substrate (where no hole existed) and disappearing completely-the ultimate visual anti-predator behavior. This same behavior was observed in the "mimic octopus" Thaumoctopus mimicus on the sand plains in Indonesia (Norman and Hochberg, 2005; Hanlon et al., 2008), and we have observed it in Amphioctopus burryi in Saba on this same research expedition; it is a behavior probably conserved among octopuses in open sand habitats worldwide.

\section{Acknowledgments}

We are indebted to Sea \& Learn, Saba Island, for hosting our research program on cephalopods. In particular, Lynn Costenaro, John Magor, and Alex van der Kroft provided outstanding coordination of divers and dive boats. The Hartleib and Chambers families furnished accommodations and computer facilities during this field work. Dave and Noreen Downs, and Dave and Doris Krumholz provided valuable diving assistance. Michael Chammaa and Oliver Hartleib found the first mimic octopus in Saba, and Paul Humann and Ned DeLoach first published the hint of this behavior in their 2002 book; they kindly allowed us to reproduce several of their photographs in this paper. Howard and Michelle Hall generously supplied video of octopus mimicry of flounders from Belize, and Dee Scarr contributed observations of octopus mimicry in Bonaire. Special thanks to Lazaro Ruda, who graciously shared his observations, photographs, and video of octopuses in southeast Florida. David Kooistra of Saba Marine Park kindly supplied some boat time and diver assistance. RTH thanks the Sholley Foundation and ONR grant N000140610202 for partial support. ACW thanks the Our World-Underwater Scholarship Society, and AB is grateful for funding from POCI 2010 and Fundo Social Europeu through the Fundação para a Ciência e a Tecnologia, Portugal. Christine Huffard provided a thorough and useful review of the penultimate draft of this manuscript.

\section{Literature Cited}

Allen, J., L. Mäthger, A. Barbosa, and R. Hanlon. 2009. Cuttlefish use visual cues to control three-dimensional skin papillae for camouflage. J. Comp. Physiol. A 195: 547-555.

Borst, A., and M. Egelhaaf. 1989. Principles of visual motion detection. Trends Neurosci. 12: 297-305.

Cott, H. B. 1940. Adaptive Coloration in Animals. Methuen, London.

Edmunds, M. 1974. Defense in Animals. A Survey of Anti-Predator Defenses. Longman Group, New York.

Edmunds, M. 2000. Why are there good and poor mimics? Biol. J. Linn. Soc. 70: 459-466.

Endler, J. A. 1978. A predator's view of animal color patterns. Evol. Biol. 11: 319-364.

Endler, J. A. 1981. An overview of the relationships between mimicry and crypsis. Biol. J. Linn. Soc. 16: 25-31.

Froese, R., and D. Pauly, eds. 2009. FishBase. [Online] World Wide Web electronic publication. Available: www.fishbase.org. Orig. vers. 09/2009.

Gilbert, F. 2005. The evolution of imperfect mimicry. Pp.231-287 in Insect Evolutionary Ecology, M. D. E. Fellowes, G. J. Holloway, and J. Rolff, eds. CABI, Wallingford, UK.

Golding, Y. C., A. R. Ennos, and M. Edmunds. 2001. Similarity in flight behavior between honeybee Apis mellifera (Hymenoptera: Apidae) and its presumed mimic, the dronefly Eristalis tenax (Diptera: Syrhidae). J. Exp. Biol. 204: 139-145.

Grimpe, G. 1922. Systematiche Uebersicht der Europaischen Cephalopoden. Sitzber. Naturf. Ges. Leipsig 9: 36.

Hailman, J. P. 1977. Optical Signals: Animal Communication and Light. Indiana University Press, London.

Hall, K. C., and R. T. Hanlon. 2002. Principal features of the mating system of a large spawning aggregation of the giant Australian cuttlefish Sepia apama (Mollusca: Cephalopoda). Mar. Biol. 140: 533-545.

Hanlon, R. T. 1988. Behavioral and body patterning characters useful in taxonomy and field identification of cephalopods. Malacologia 29: $247-264$.

Hanlon, R. T. 2007. Cephalopod dynamic camouflage. Curr. Biol. 17: R400-R404.

Hanlon, R. T., and J. B. Messenger. 1996. Cephalopod Behavior. Cambridge University Press, Cambridge.

Hanlon, R. T., J. W. Forsythe, and S. V. Boletzky. 1985. Field and 
laboratory behavior of "macrotritopus larvae" reared to Octopus defilippi Verany, 1851 (Mollusca: Cephalopoda). Vie Milieu 35: 237-242.

Hanlon, R. T., J. W. Forsythe, and D. E. Joneschild. 1999. Crypsis, conspicuousness, mimicry and polyphenism as antipredator defences of foraging octopuses on Indo-Pacific coral reefs, with a method of quantifying crypsis from video tapes. Biol. J. Linn. Soc. 66: 1-22.

Hanlon, R. T., M.-J. Naud, P. W. Shaw, and J. N. Havenhand. 2005. Behavioral ecology: transient sexual mimicry leads to fertilization. Nature 430: 212.

Hanlon, R. T., L. A. Conroy, and J. W. Forsythe. 2008. Mimicry and foraging behavior of two tropical sand-flat octopus species off North Sulawesi, Indonesia. Biol. J. Linn. Soc. 93: 23-38.

Hanlon, R. T., C. Chiao, L. Mathger, A. Barbosa, K. C. Buresch, and C. Chubb. 2009. Cephalopod dynamic camouflage: bridging the continuum between background matching and disruptive coloration. Philos. Trans. R. Soc. B 364: 429-437.

Huffard, C. L. 2006. Locomotion by Abdopus aculeatus (Cephalopoda: Octopodidae): walking the line between primary and secondary defenses. J. Exp. Biol. 209: 3697-3707.

Huffard, C. L. 2007. Ethogram of Abdopus aculeatus (D'Orbigny, 1834) (Cephalopoda: Octopodidae): Can behavioural characters inform octopodid taxonomy and systematics? J. Molluscan Stud. 73: 185-193.

Huffard, C. L., F. Boneka, and R. J. Full. 2005. Underwater bipedal locomotion by octopuses in disguise. Science 307: 1927.

Humann, P., and N. DeLoach. 2002. Reef Creature Identification: Florida-Caribbean-Bahamas. New World Publications, Jacksonville, FL.

Kier, W. M., and K. K. Smith. 1985. Tongues, tentacles and trunks: the biomechanics of movement in muscular-hydrostats. Zool. J. Linn. Soc. 83: 307-324.

Krajewski, J. P., R. M. Bonaldo, C. Sazima, and I. Sazima. 2009. Octopus mimicking its follower reef fish. J. Nat. Hist. 43: 185-190.

Norman, M. D. 2000. Cephalopods: A World Guide. ConchBooks, Hackenheim, The Netherlands.

Norman, M. D., and F. G. Hochberg. 2005. The "mimic Octopus" (Thaumoctopus mimicus $\mathrm{n}$. gen. et sp.), a new octopus from the tropical Indo-West Pacific (Cephalopoda: Octopodidae). Molluscan Res. 25: $57-70$.

Norman, M. D., J. Finn, and T. Tregenza. 1999. Female impersonation as an alternative reproductive strategy in giant cuttlefish. Proc. R. Soc. Lond. B 266: 1347-1349.

Norman, M. D., J. Finn, and T. Tregenza. 2001. Dynamic mimicry in an Indo-Malayan octopus. Proc. R. Soc. Lond. B 268: 1755-1758.
Packard, A. 1972. Cephalopods and fish: the limits of convergence. Biol. Rev. 47: 241-307.

Ramachandran, V. S., C. W. Tyler, R. L. Gregory, D. Rogers-Ramachandran, S. Duensing, C. Pillsbury, and C. Ramachandran. 1996. Rapid adaptive camouflage in tropical flounders. Nature 379: $815-818$.

Rees, W. J. 1954. The Macrotritopus problem. Bull. Br. Mus. Nat. Hist., Zool. 2: 69-99.

Srinivasan, M. V., and M. Davey. 1995. Strategies for active camouflage of motion. Proc. R. Soc. Lond. B 259: 19-25.

Srygley, R. B. 1999. Locomotor mimicry in Heliconius butterflies: contrast analyses of flight morphology and kinematics. Philos. Trans. $R$. Soc. Lond. B 354: 203-214.

Starrett, A. 1993. Adaptive resemblance-a unifying concept for mimicry and crypsis. Biol. J. Linn. Soc. 48: 299-317.

Steene, R. 1998. Coral seas. Ocean Realm, Autumn 1998: 74-85.

Stevens, M. 2007. Predator perception and the interrelation between different forms of protective coloration. Proc. R. Soc. Lond. B 274: $1457-1464$.

Stevens, M., and S. Merilaita. 2009a. Animal camouflage: current issues and new perspectives. Philos. Trans. R. Soc. Lond. B 364: $423-427$.

Stevens, M., and S. Merilaita. 2009b. Defining disruptive coloration and distinguishing its functions. Philos. Trans. R. Soc. Lond. B 364: 481-488.

Stevens, M., I. C. Cuthill, J. Sheppard, T. Maddocks, T. Troscianko, and C. A. Parraga. 2004. Disruptive colouration and background pattern matching. Perception 33: 35.

Stevens, M., I. C. Cuthill, A. Parraga, and T. Troscianko. 2007. The effectiveness of disruptive coloration as a concealment strategy. Pp. 49-65 in Visual Perception (Part 2): Progress in Brain Research, S. Martinez-Conde, S. L. Macknik, L. M. Martinez, J.-M. Alonso, and P. U. Tse, eds. Elsevier, Amsterdam.

Thayer, G. H. 1909. Concealing-Coloration in the Animal Kingdom. An Exposition of the Laws of Disguise Through Color and Pattern: Being a Summary of Abbott H. Thayer's Disclosures. Macmillan, New York.

Webb, P. W. 2002. Kinematics of plaice, Pleuronectes platessa, and cod, Gadus morhua, swimming near the bottom. J. Exp. Biol. 205: 2125-2134.

Wells, M. J. 1990. The dilemma of the jet set. New Scientist 17: 44-47. Wickler, W. 1968. Mimicry. Weidenfeld and Nicolson, London. 